\title{
Sustainable Management of Household Garbage- Status of Citizens behavior and participation A Case Study of Khenifra region - Morocco
}

\author{
Elhamdouni Driss \\ Arioua Abdelkrim \\ University Sultan Moulay Slimane, Faculty of Sciences and Technologies, \\ Department of Earth Sciences, Management and Valorisation of Water \\ Resources and Remote Sensing Team, Mghila, Beni Mellal, Morocco \\ Aba Baaddi \\ Khenifra Province, Division of Local Communities, \\ Service of the Planning and Equipment, Khenifra, Morocco

\section{Karaoui Ismail \\ Elfiraoui Fatiazahrae} \\ Ait Ouhamchich Kamal \\ University Sultan Moulay Slimane, Faculty of Sciences and Technoloqies, \\ Department of Earth Sciences, Management and Valorisation of Water \\ Resources and Remote Sensing Team, Mghila, Beni Mellal, Morocco
}

\section{Doi:10.19044/esj.2018.v14n20p61 URL:http://dx.doi.org/10.19044/esj.2018.v14n20p61}

\begin{abstract}
Like the other Moroccan territories, Khenifra region faces many problems in household waste management, due to produced waste quantities, the insufficient infrastructure and the low level of environmental education. Khenifra region contain a diversified and fragile natural environment. In this work, we used the social approach that aims to diagnose the current state of waste management in the study area and in order to propose appropriate solutions for a successful management, as results, the existence of several deficiencies and constraints in the daily operations of collection and landfilling. Surveys and field visits have been carried out showed that the human and material resources used in the west management operation are not sufficient and not respect the environmental conditions. Facing these constraints require, an effective strategy for management of household waste in this territory has been developed to ensure a better collect and treatment. Thus, our proposed strategy cannot succeed without population involved, it requires collaboration between municipalities, delegated companies and citizens as well.
\end{abstract}


Keywords: Waste Management, Social Approach, Surveys, Khenifra regionMorroco.

\section{Introduction:}

Household solid waste management (HSWM) is a major environmental problematic that bothers Moroccan local authorities. This problematic is owed to several factors such as the amounts of waste produced, insufficient infrastructure and the low level of education and environmental awareness (Elhamdouni, 2017). Other common issues to the Moroccan territories are the galloping demography and uncontrolled urbanization that weaken the implemented waste management systems and degraded roads which make the west collect more difficult (Gapyisi, 1989). Diabagate (2009) confirms that one of the major problems that Moroccan territories suffer from is the household waste and uncontrolled urbanization.

Henceforth, waste management should be registered in the perspective of sustainable development whose basic principles is forwarding a viable environment (costs of environmental degradation, maintenance of natural capital (eco-compatible releases) and the protection of it, thus contributing to an equitable socio-economic development (Najih, 2015 and Aina, 2006). In front of the waste problem acuteness and the importance of its political social cultural and environmental issue to Morocco, there has been in recent years a new dynamic and political will, expressed by Governments, to put into action a comprehensive strategy of waste management throughout the national territory (Arco environment, 2015). In this context, these studies contribute to aid the decision-maker to provide the reference data on the current state household garbage management in Khenifra province.

For that reason, our assumptions focus on attitudinal and behavioral changes in the long term and aim to compare the effectiveness of an engagement strategy to a persuasive environmental communication. This field work is also an opportunity to collect information on practices and attitudes relating to the prevention. Indeed, the accessibility of this tool will enable decision-makers to conduct periodic studies to track changes and developments of waste management. This will allow them to optimize the choice in programs that might help resolve the problem of solid waste (recovery, recycling, treatment, etc.).

\section{Material and Methods Study area}

Khenifra province is located in the north of Beni Mellal-Khenifra region, is one of the twelve regions created by territorial division as part of the advanced regionalization (figure 1). Administratively, the province split into 
22 municipalities including two in urban and twenty in the rural area. Accidental reliefs and an altitude worsening from West to East characterize this province. They vary from $306 \mathrm{~m}$ in the North-West and the South of the province to $2210 \mathrm{~m}$ in South East and North. The province climate is continental Mediterranean, it is characterized by a cold and rainy winter with periods of snow in the high mountains and a hot and dry summer with stormy periods.

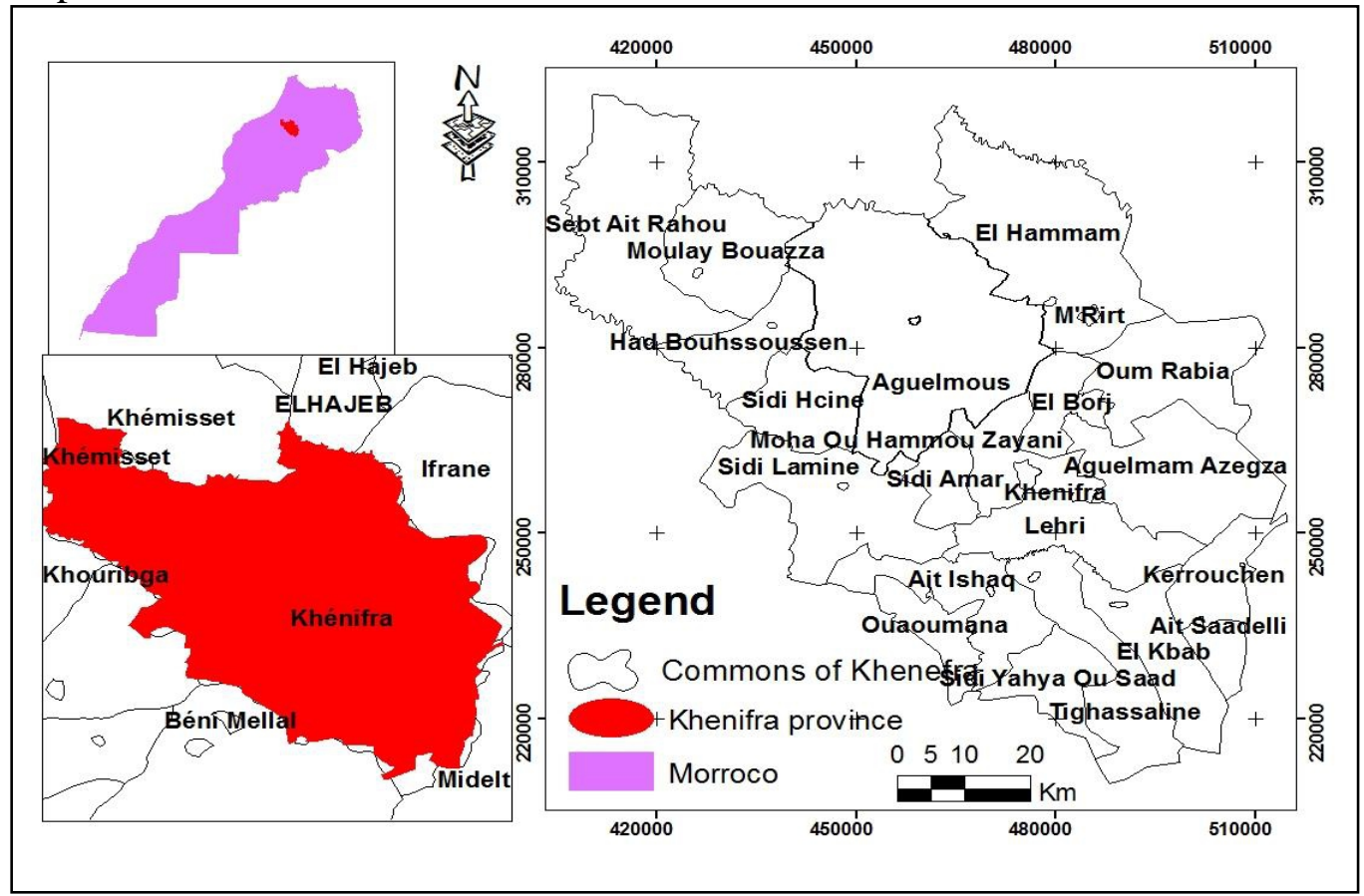

Figure 1: Study area Location

\section{Inhabitants Survey}

\section{The Sectors choice}

Since Khenifra province has a large area, the heterogeneous characteristics of HSW and the influence of the households' standard of living on their composition and their quantification, the study proceeded to divide the province into two main areas (figure 2), urban sectors and rural ones. Based on the standard of living that is essentially determined by the quality and nature of the habitat, we divided the urban sectors into three strata (neighborhoods). Random sampling is then operated to define households surveyed. 


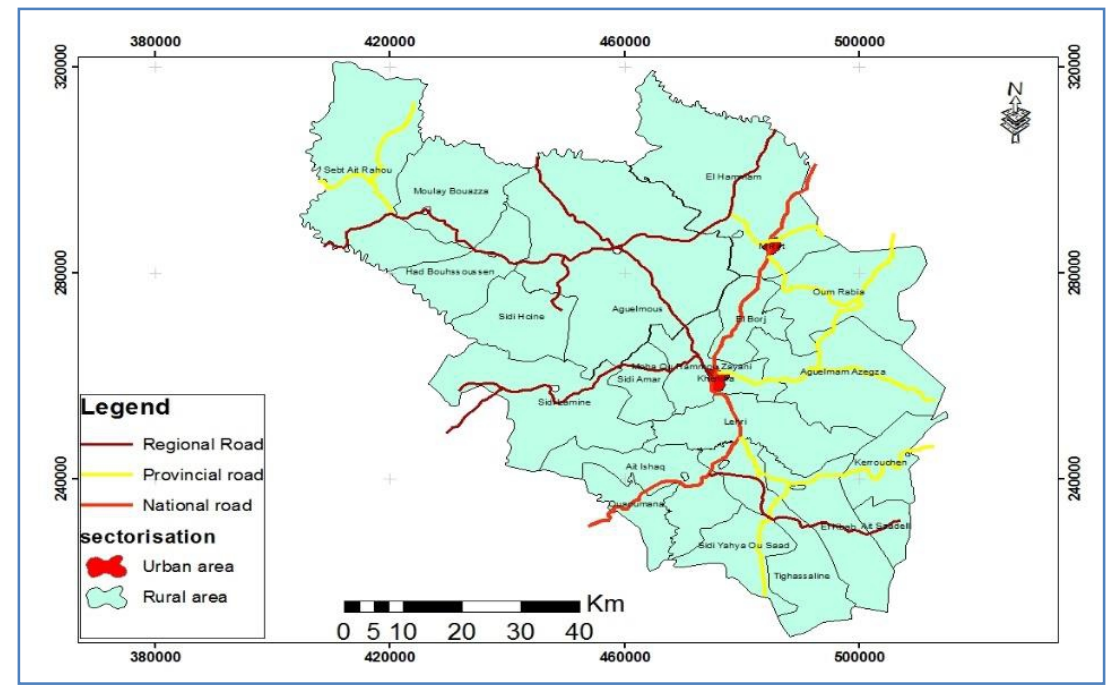

Figure 2: Prospecting area Sectorisation

\section{Purpose of the survey}

The preliminary household survey is an essential component of household waste characterization (HW). It is anonymous, something which contributes strongly to the membership of the target population (Aloueimine, 2006).

The used questionnaire brings together a set of questions directed to people of various social classes, sexes and ages: the household's owner or their wives. This survey allowed us to collect useful and essential information including household's size and their practice in waste management.

The collected information from investigations, are treated for synthesis and decision-making for a HSWM strategy.

\section{The used approach}

The figure below represents the adopted methodology in this study (figure $3)$.

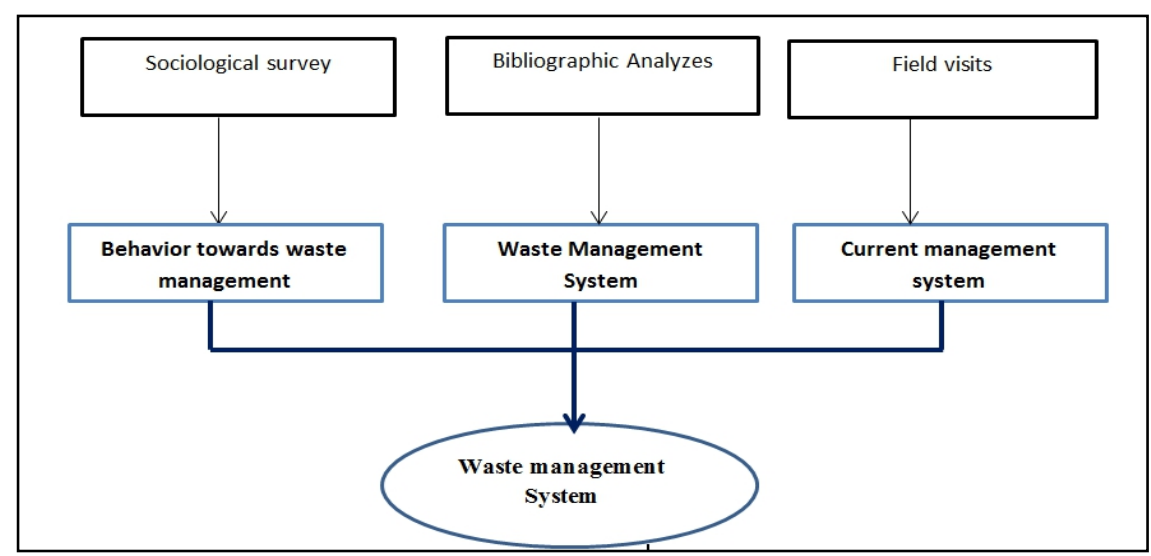

Figure 3: Diagram of the used approach 


\section{Results and discussion \\ Households' size}

The survey allowed us to collect information about the people who participated in the study. This information is aiming to understand and know the participation degree of citizens' in the household waste management. The number of surveyed households is 447 , representing rural and urban areas. The investigation showed that the household sizes decline with the increase in the standard of living.

These household sizes are calculated for $t$ a $; n-1$ (see table t-Student $o$ t-distributions) for the households number with standing (table 1) (Aloueimine, 2006).

Table1: Households' Sizes.

\begin{tabular}{|c|c|c|c|c|c|c|}
\hline \multirow[t]{2}{*}{ Settings } & \multirow[t]{2}{*}{ Rural area } & \multicolumn{4}{|c|}{ Urban area } & \multirow{2}{*}{$\begin{array}{l}\text { Khenifra } \\
\text { Province }\end{array}$} \\
\hline & & $\begin{array}{c}\text { Low } \\
\text { standing }\end{array}$ & $\begin{array}{c}\text { Middle } \\
\text { standing }\end{array}$ & $\begin{array}{c}\text { High } \\
\text { standing }\end{array}$ & $\begin{array}{c}\text { Khenifra } \\
\text { city }\end{array}$ & \\
\hline $\begin{array}{l}\text { Sampling } \\
\text { area }\end{array}$ & $\begin{array}{c}6 \\
\text { municipaliti } \\
\text { es }\end{array}$ & $\begin{array}{c}\text { Tiallaline } \\
\text { Neighborhoo } \\
\text { d }\end{array}$ & $\begin{array}{c}\text { Agricol } \\
\text { Neighborho } \\
\text { od }\end{array}$ & $\begin{array}{c}\text { Cooperative } \\
\text { Neighborhoo } \\
\text { d }\end{array}$ & $\begin{array}{c}3 \\
\text { Neighborhoo } \\
\text { ds }\end{array}$ & $\begin{array}{c}7 \\
\text { municipaliti } \\
\text { es }\end{array}$ \\
\hline $\begin{array}{l}\text { Number of } \\
\text { households }\end{array}$ & 177 & 105 & 91 & 74 & 270 & 447 \\
\hline $\begin{array}{c}\text { Number of } \\
\text { persons }\end{array}$ & 834 & 427 & 348 & 268 & 1043 & 1877 \\
\hline $\begin{array}{c}\text { Average } \\
\text { size } \\
\text { household }\end{array}$ & 4.71 & 4.06 & 3.83 & 3.63 & 3.84 & 4.27 \\
\hline $\begin{array}{c}\text { SD ( } \\
\text { Standard } \\
\text { Deviation) }\end{array}$ & 5 & 3 & 3.2 & 3.37 & 3.19 & 4.09 \\
\hline $\begin{array}{c}\text { Confidence } \\
\text { interval }\end{array}$ & \pm 4.13 & \pm 4.60 & \pm 4.32 & \pm 4.10 & \pm 4.35 & \pm 4.23 \\
\hline
\end{tabular}

Population projection and the amount produced waste

The population projection in Khenifra province during the period 2016-2044 was carried out by the following formula (RGPH, 2014): $P_{n}=P_{0}\left(1+T_{a}\right)^{n}$

With: $\mathrm{Pn}=$ projected population; $\mathrm{P}_{0}=$ reference population; $\mathrm{Ta}=$ population growth rate and $\mathrm{n}=$ years numbers.

The amounts of waste produced at different horizons are estimated using the following relation:

$$
\mathrm{Q}_{\mathrm{Ai}}=\mathrm{Q}_{0}(1+\mathrm{Tc})\left(\mathrm{Ai}_{\mathrm{i}} \mathrm{A}_{0}\right)
$$

With, $\mathrm{Q}_{\mathrm{Ai}}$ : waste amount in $\mathrm{t} / \mathrm{year}$ in year $\mathrm{A}_{\mathrm{i}}$ (year of projection), $\mathrm{Q}_{0}$ : amount of waste in $t / y e a r$ corresponding to the year of reference $A_{0}$, Tc: Average annual growth rate retained (Ratio). The results of these simulations are expressed in the following table. 
Table 2: Household waste production quantities in the next 28 years

\begin{tabular}{|c|c|c|c|c|c|}
\hline Years & $\mathbf{2 0 1 6}$ & $\mathbf{2 0 2 4}$ & $\mathbf{2 0 3 6}$ & $\mathbf{2 0 4 0}$ & $\mathbf{2 0 4 4}$ \\
\hline Population & 235184 & 247767 & 266825 & 275952 & 283912 \\
\hline $\begin{array}{c}\text { Amount of estimated } \\
\text { waste t/year }\end{array}$ & 54363 & 57944 & 62554 & 64171 & 65828 \\
\hline
\end{tabular}

\section{Composition of solid waste}

The Khenifra region waste, as most of Morocco's waste, is characterized by important humidity close to $70 \%$ due to high organic matter content. Waste composition studies were conducted at the national level and in some Moroccan cities, including Beni Mellal (Mechadi, 2016) and Meknes (Eau globe, 2012).

Visiting the discharge of the study area allowed us to estimate the origin, nature and composition, waiting to perform a complete and well-detailed waste characterization. Organic matter represents the highest amount of the waste sent to the landfill (figure 4) (Elhamdouni, 2016). This composition is illustrated in the following figure:

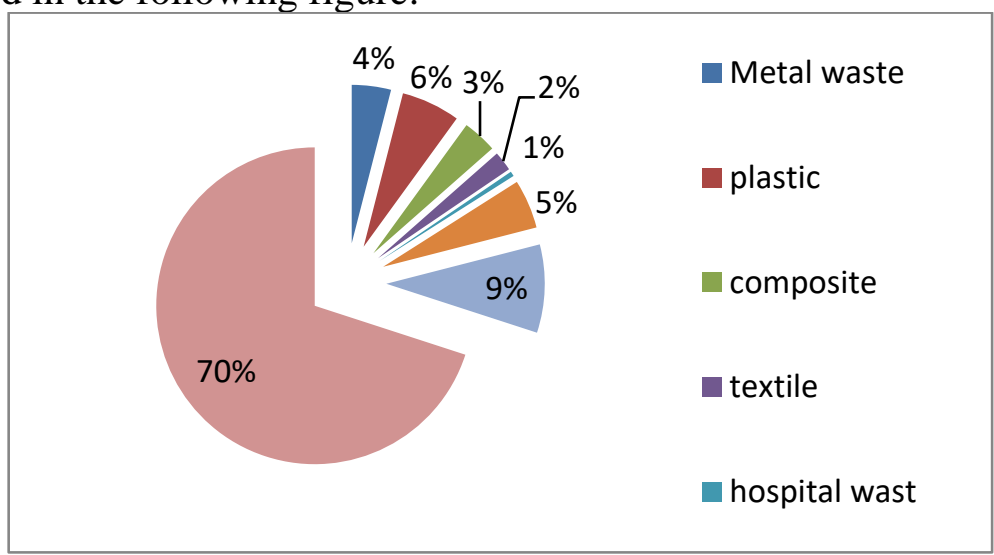

Figure 4: Estimated composition of Khenifra region solid waste

These analyses showed that waste organic fraction is close to the national average (Mechdi, 2017, Rassam, 2012).

\section{Citizens participationin waste management in Khenifra region}

To understand people behaviors towards household waste in this province. The questionnaire was divided into 4 parts whose results after treatment are as follows:

\section{Part 1: The waste management inside houses:}

The household waste production started inside houses, and households are interviewed on:

- Who takes care of waste management? 
-The frequency of waste disposal;

The results of the survey showed that among $71 \%$ of households (figure 5), it's the mother who deal with waste management inside the house, $19.5 \%$ is the father and children also involved with a percentage of $10 \%$. According to the obtained results, the role of women in waste management is essential.

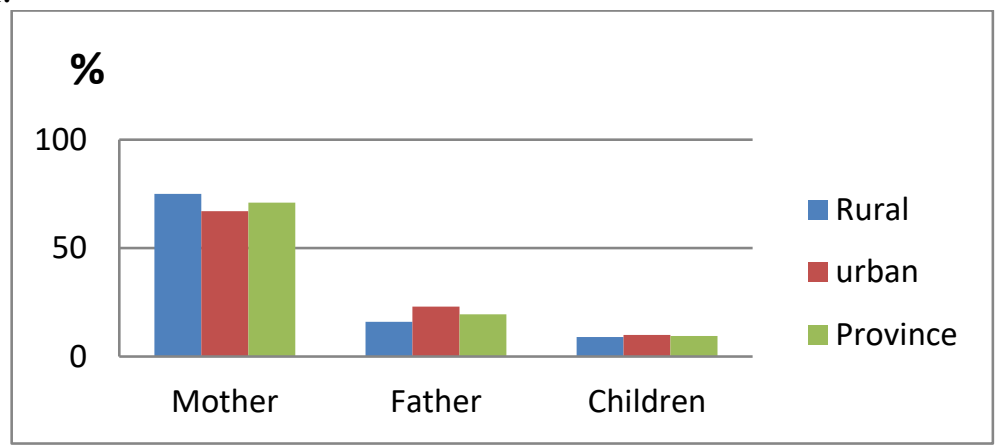

Figure 5: Family member who takes care of waste management.

- The results also show that the majority of urban households get rid of their waste during the night (43\%), the morning 33\% while 24\% without accuracy (Figure 6). On the other hand in rural areas, the majority of households dispose of their waste in the morning (75\%).

Also almost all of the houses (91\%) get rid of their waste with frequency once/day (Figure 7). These percentages figures explain well the problems encountered and reported by the delegated company in the town of Khenifra. It should be noted that waste collection is not done regularly in rural areas. Rural communities proceed to eliminate the accumulated waste, which creates the black spots, by incineration.

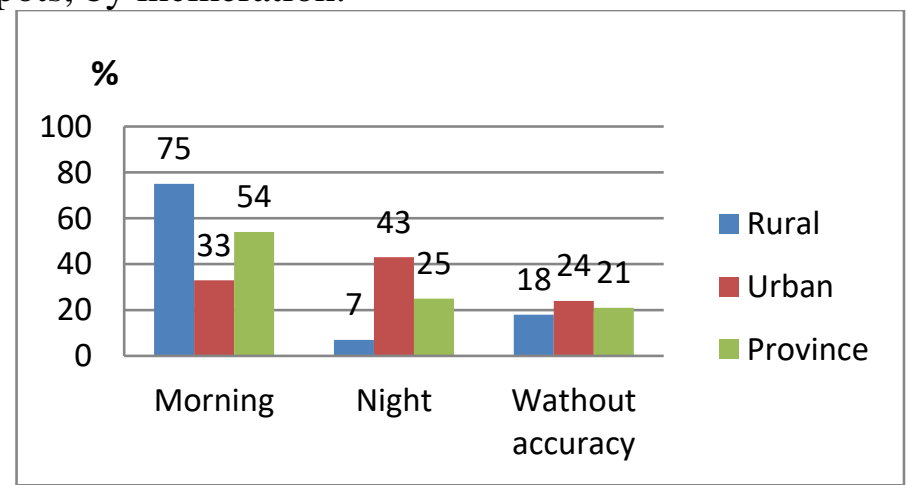

Figure 6: Schedules of household waste disposal in the province of Khenifra 


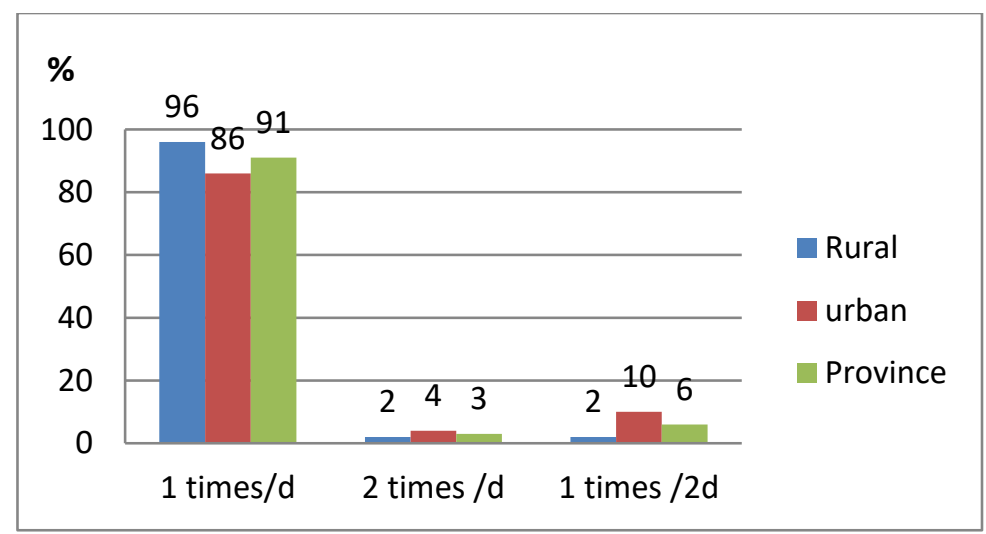

Figure 7: Output frequency of the trash

\section{Part 2: The problems of waste management in the neighborhoods}

According to the interview that we conducted with the khenifra province population we deduced that $49 \%$ inhabitants say's that they find it difficult to get their waste ride in the urban area because of the insufficiency and/or lack of bins. While $21 \%$ inhabitants think that these difficulties are related to the disruption of collection schedules managed by the delegated company. In addition, $17 \%$ claimed that these management issues are related to incorrect and irresponsible people behavior (figure 8 and 9).

However, in rural areas, almost all population says that this problem is more serious and related to the total absence of the bins (figure 9).

These deductions confirm the remarks made during the field trip visits done in the study area centers. In fact, we found that collection in rural areas is made in a direct and traditional way by the municipality itself that has no bins. Moreover, the collection is done irregularly which intensifies the problems.

In the urban areas, the lack of installation of bins is noticeable in some neighborhoods where the population density is high. This brings us to think of carrying out a study of optimization of the collection means in the future.

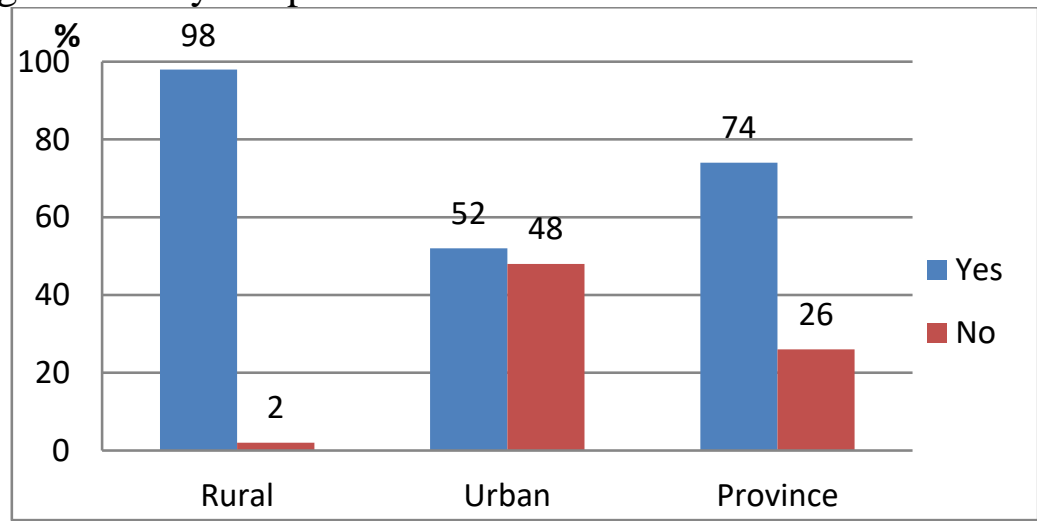

Figure 8: Statement of the problems 


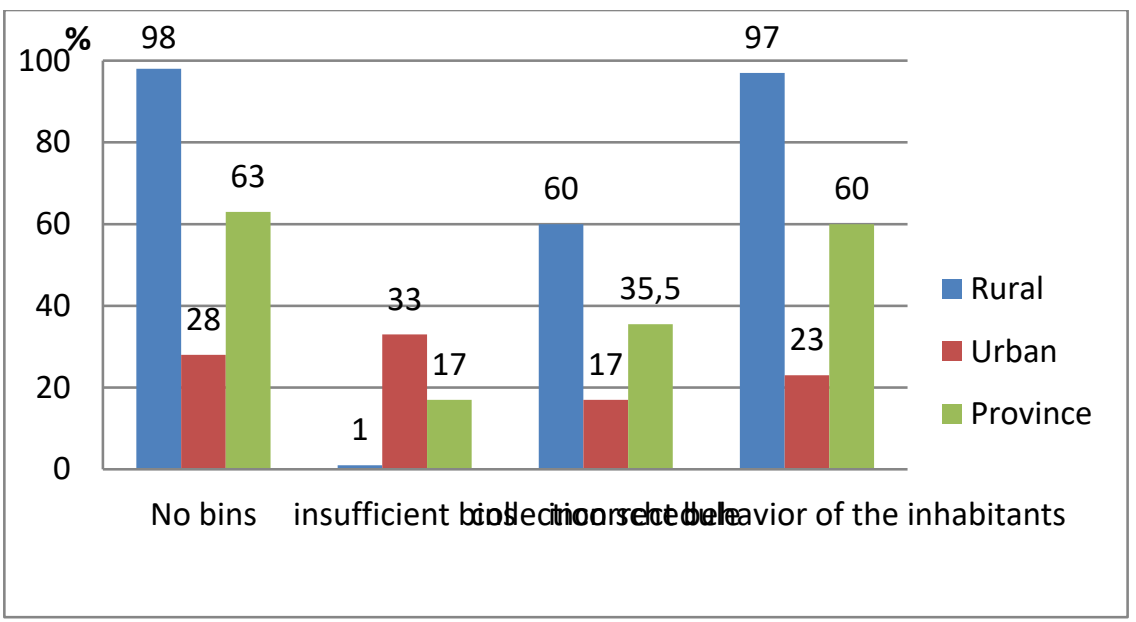

Figure 9: Classification of the problems

The remoteness, inadequacy and bins lack, inadequate citizenship, waste collection disruption schedules impose $99 \%$ of families in rural areas and $44 \%$ in urban areas to get rid of their garbage in the street (figure 10).

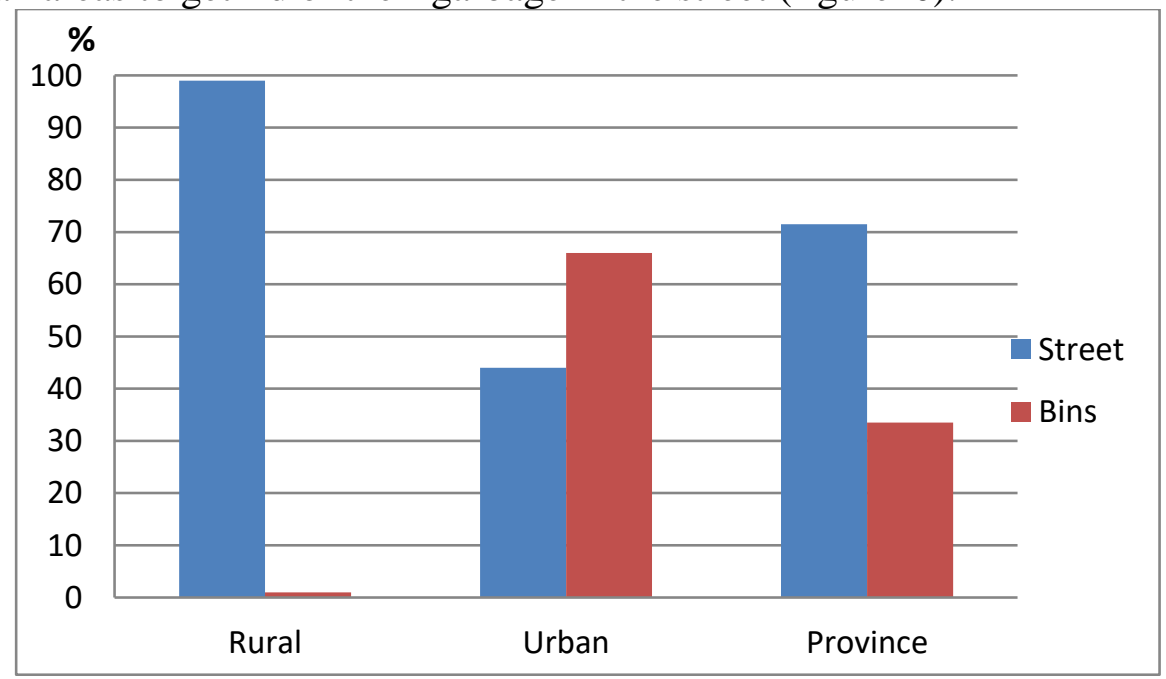

Figure 10: Dumping Place

The survey data analysis revealed that the majority of households in rural areas are not satisfied with the current waste management, while $50 \%$ of urban families have a fair assessment on the current state of the garbage collection in the city (Figure 11).

This household solid waste management assessment explains and confirms the existence of illegal dumps in khenifra province. 


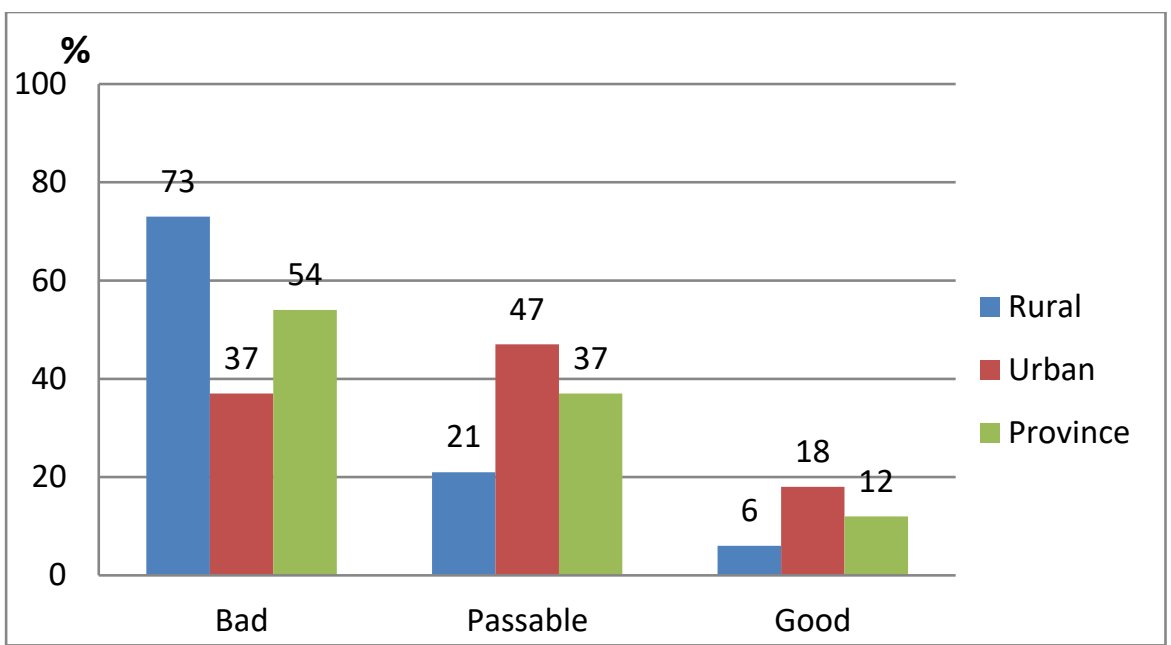

Figure 11: current management Appreciation in the province

\section{Part 3: Inhabitants Interest in the waste field}

This part aims to know how much the khenifra province inhabitants are interested in the field of waste in order to measure their awareness of the impacts generated by their waste.

The survey results revealed that almost $45 \%$ (figure 12) of the peoples are not aware about the waste management procedure. On the other hand, the waste does not arouse their enthusiasm once evacuated from their houses; there is an obvious relation between the distance to the waste and its risk (Najih, 2014).

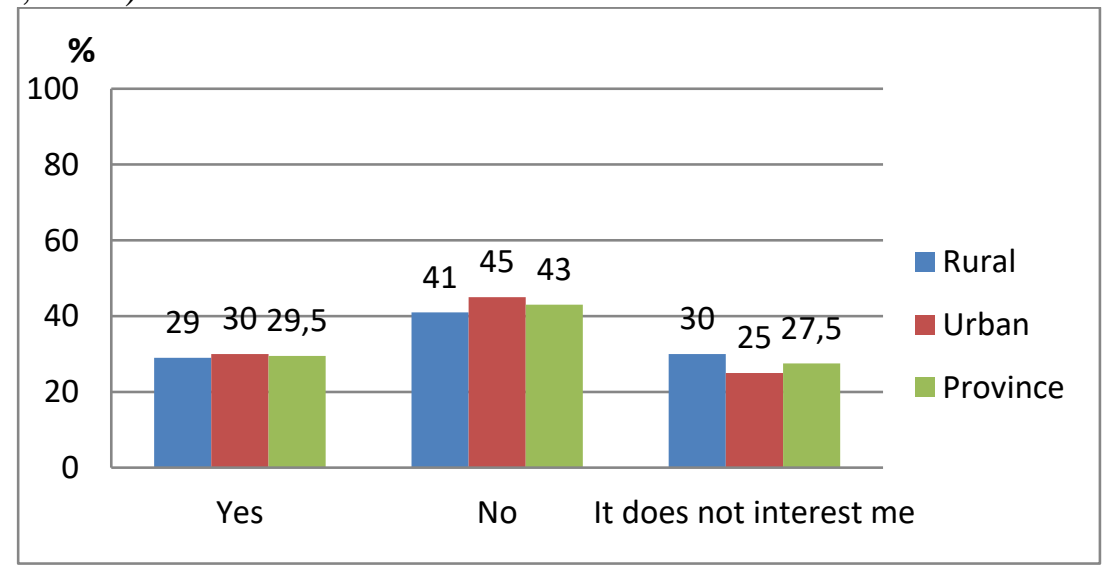

Figure 12: The Khenifra province inhabitants who know the future of waste

\section{Part 4: possibility of improving the financial involvement of citizens}

Sorting at source is an essential step in waste management systems. However, in the national level, this operation is not yet used, but there are some encouraging experiments. This part of the questionnaire focuses on the degree of residents' knowledge about sorting and recycling procedure. 
The obtained results showed that $54 \%$ of urban residents have an idea and being informed of sorting. On the other hand, $75 \%$ of households in rural areas have no idea about this notion (Figure 13).

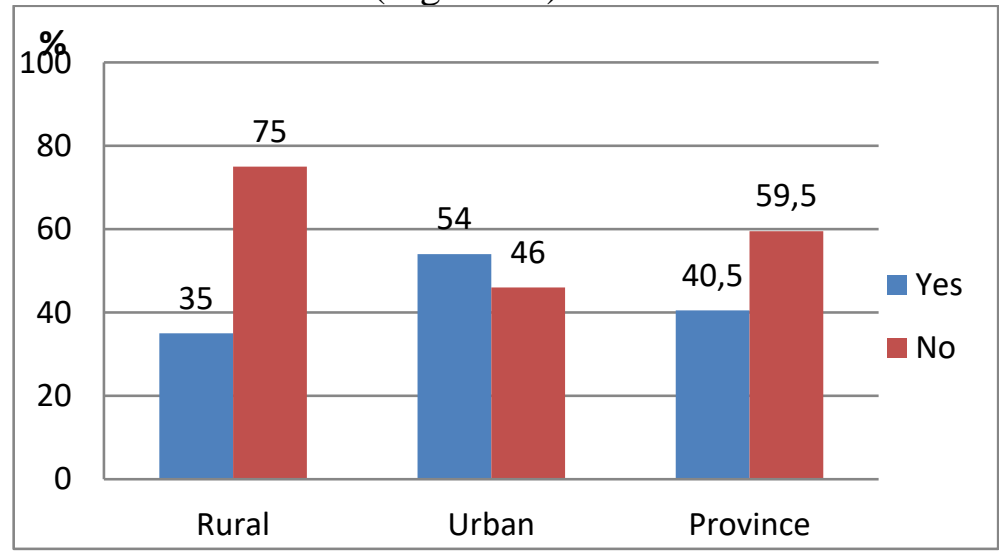

Figure 13: Households that have an idea about sorting in Khenifra province.

The results show that the majority of surveyed households (66\%) in the urban area agree about sorting in the source (house) (Figure 14), while 77\% of the inhabitants of rural households refuse to do it. As a result, $28 \%$ of the population of Khenifra province accepts to do sorting procedure.

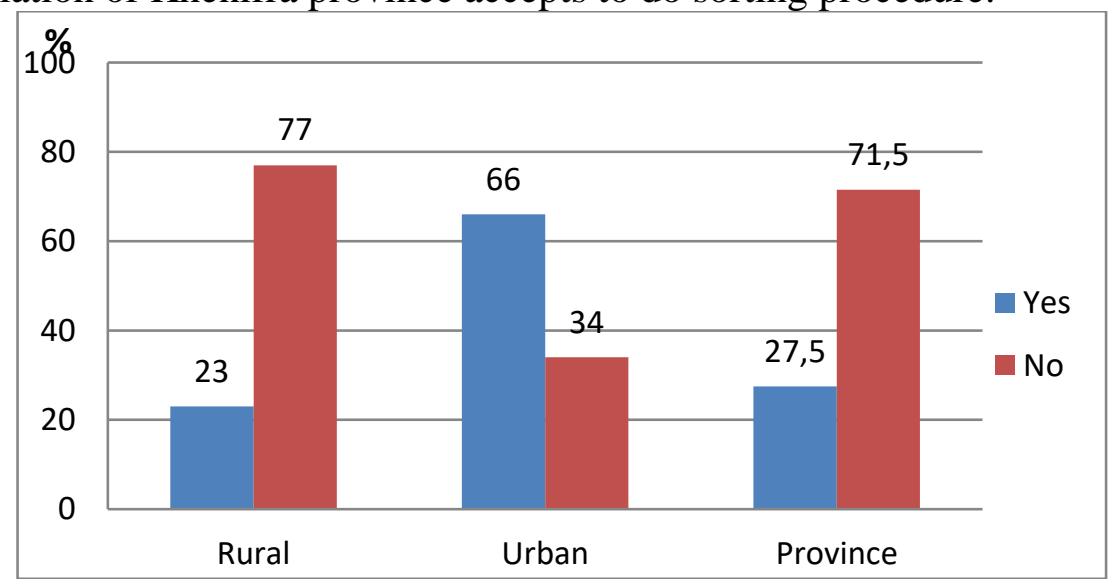

Figure 14: Households accepting to do the sorting in the province of Khenifra

To evaluate the inhabitants' willingness to get involved in the process of changing the current state, we have interviewed the residents about the possibility of being financially involved to modernize the household waste management sector.

The obtained results showed that $70 \%$ of households refuse to pay an additional fee to upgrade the current state of waste management. In addition, the results featured in the diagram (figure 15), showed that the percentage of the population agreeing to pay is higher in urban than in rural areas. This 
indicates that the type of this sector reflects the level of households' standard of living, which is an important factor that needs to be considered in setting up an appropriate management system to the Khenifra province. Studies conducted in other countries on the applicability of the royalty fee show that this tool cannot always be used as a means to improve the sector and to ensure the involvement of citizens, in France, the study of François Benard (2008) shows that the incentive fee seems to be a relevant tool of intervention on the behavior. However, Fullerton and Kinnaman (1995) have shown that a tax or a royalty fee is related to volumes of the produced garbage, something that cause households to illegally divert their waste by burning or dropping them in nature (Kouame, 2013).

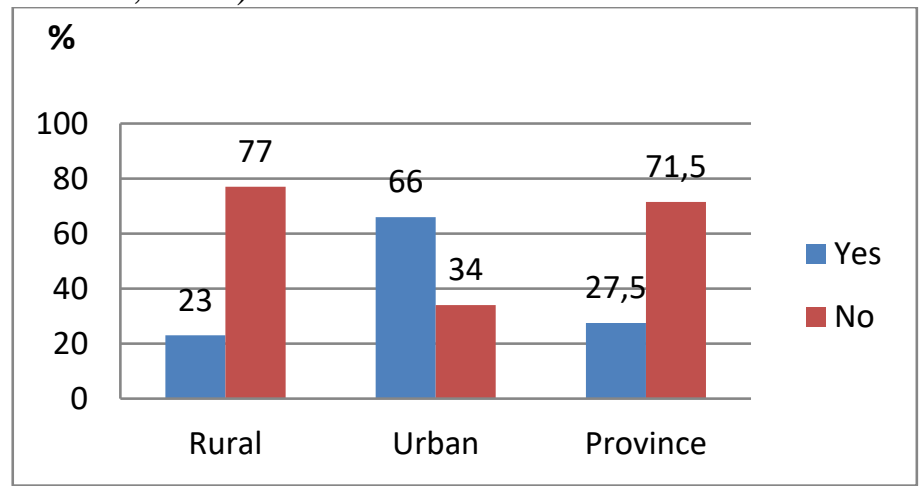

Figure 15: Households in the province that are willing to pay.

\section{Appropriate management system scenarios in the study area}

The suitable management system choice to manage household waste in Khenifra province requires the active participation of the population and decision makers, taking into account the financial capacity. The analysis of the obtained results, bibliographic studies (Najih, 2015) and (Makan, 2013) and according to their surveys and field visits allowed us to propose two scenarios:

- Scenario 1: Taking into account the particularity of the province, the human and material resources and the current situation. The most appropriate system is to collect the mixed HW, then mechanically sort them in a sorting center. Mechanical sorting allows recovering recyclable materials (glass, plastics, cardboard, metals). On the other hand, the remaining waste (biodegradable) undergoes a biological treatment (composting) or are buried in the locker (Figure 16). 


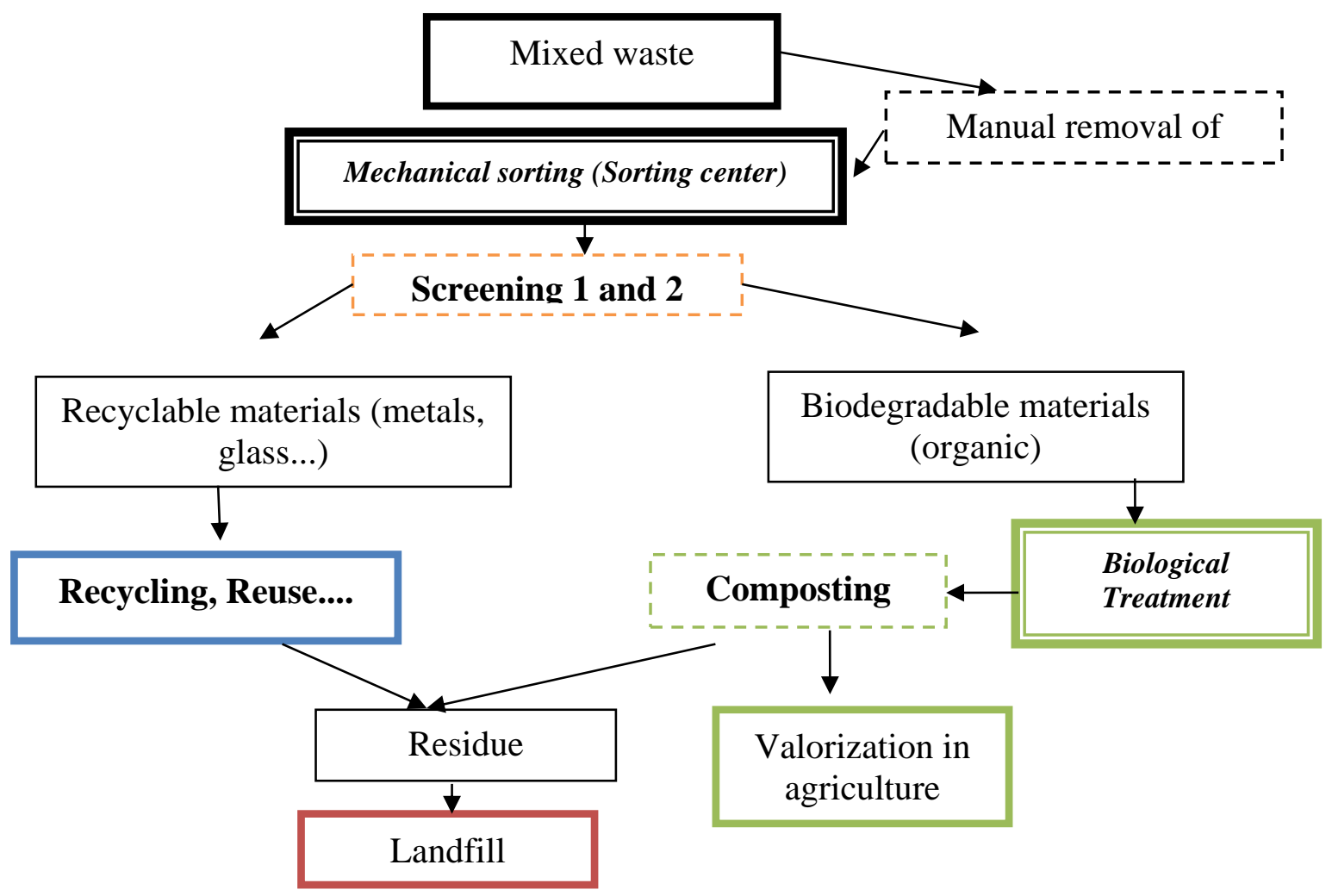

Figure 18: Representation of the household waste management system without sorting at source

- Scenario 2: To date, sorting at the source is considered a random service whose success is dependent on the membership and voluntary collective and sustainable citizens' engagement .

The province of Khenifra may adopt this scenario of treatment, because it is simpler, but it requires an effective participation of the population putting into action human resources and important materials. This household waste management system, which offers a reduction in the quantities of waste, cost control and the protection of the environment, is the most appropriate. 


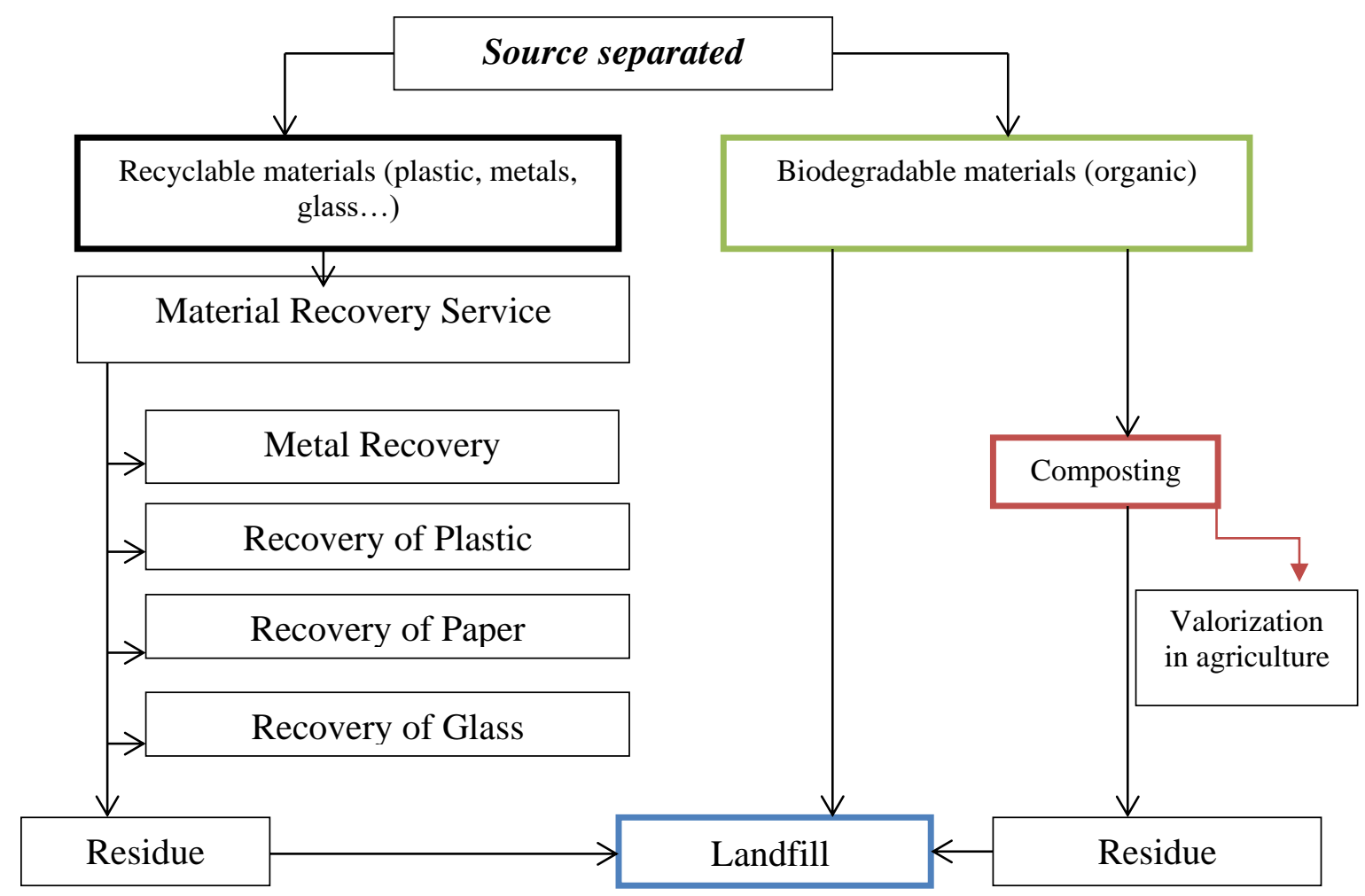

Figure 19: Household waste management system Representation with sorting at source

\section{Conclusion:}

In this article, we have relied on the social approach that consists of studying the population behaviors in Khenifra province towards their waste management to involve them in adequate and effective management strategy choice.

The survey, which was conducted in province citizens, reveals that the household waste management stream comes down to the pre-collection. Noting that all surveyed households finds it difficult to get rid of their waste. Thus, the existence of several deficiencies and constraints at day-to-day collection operations and convey landfilling has been detected. The survey also showed that environmental education of the population concerned, particularly in rural areas, is low. This requires conducting awareness workshops in these regions.

The results of this work, has allowed us to suggest two suitable patterns for better management of household waste in the study area, taking into account the particularity of the province, the human and material resources and the effective participation of the population. Noting that sorting at the 
source constitutes an essential phase in any effective household waste management system. However, the possibility of executing this operation must take into consideration the daily habits of people and ensure their accompaniment (Awareness campaigns, training organized within neighborhoods...). Media can also play an important role in this process.

Indeed, any waste management improvement, which can positively influence health and public life, cannot succeed without the participation of the interested population. It requires collaboration between municipalities, the delegated societies and citizens.

\section{References:}

1. Aina. M.P. (2006). Expertise of the technical landfill centers of urban waste in the developing countries: contributions to the development of a methodological guide and its experimental validation on sites. Thesis for a doctor, University of Limoges, 236p.

2. Aloueimine S. (2006). Methodology characterization of household waste in Nouakchott (Mauritania): contribution to the waste management and decision support tools. Thesis for a doctor. University of Limoges, 195p.

3. Arco Environment. (2015). Characterization of the garbage of Beni Mellal city. Beni Mellal, 54 p.

4. Benard F. (2008). Waste management and development of the incentive fee: example of transformation of the economic model of a public service, Cairn.info. p. $30-46$.

5. Diabagate S. (2009). Urban dynamics and management of household waste in the Bandama valley region.The case of the urban communes of Dabakala Department. Memory of DEA.

6. Eau Globe S. (2012). Report of the master plan of waste household and assimilated from the province of Khénifra. Mission 3, summary report.

7. Elhamdouni D. (2016). Contribution of geomatics applied to the environment in the selection of a suitable provincial site for a landfill. The province of KHENIFRA, Morocco. Memory of Master. 180 p.

8. Elhamdouni D., Arioua., Elhmaidi A., Aba b., Mansour D. (2017). Geomatics tools and AHP method use for a suitable municipal landfill site: Case study of Khénifra region - Morocco. Journal of Materials and Environmental Sciences, 8 and 10, Page 3612-3624. .

9. Gapyisi E. (1989). Urban challenge in Africa. Harmattan Editions, $127 p$

10. Kouame P. F. (2013), Applicability of the incentive fee for the removal of household junk in Côte d'Ivoire: case of the municipalities of Cocody and Yopougon, European Scientific Journal. 
11. Makan A. Montadar M. (2013). Sustainable management of municipal solid waste in Morocco: Application of PROMETHEE method for choosing the optimal management scheme. African Journal of Environmental and Waste Management, 1 (1), pp. 001-01.3.

12. Mechadi M., Mbarki M., Chamsi Z. (2016). Characterization of the recyclable fraction of solid waste of the Beni Mellal-Morocco-Villa Zone Territorial Commune. European Scientific Journal 12, No.23 ISSN: 1857 - 7881 (Print) e - ISSN 1857- 7431.

13. Najih A. (2015). Characterization and valorization of household waste with a view to sustainable management case of the commune of Khouribga (Morocco), Thesis for Doctor. Faculty of sciences and techniques of Beni Mellal, 172p.

14. Najih A., Habbar K. (2014). Management of household waste in the town of Khouribga (Morocco): study of the behavior of the citizen. Journal. Science Lib Editions Mersenne, 6, 140607.

15. Rassam M. (2011). Enhancing ascorbate in fruits and tubers through over-expression of the 1-galactose pathway gen GDP-1-galactose phophorylase. Plant biotechnology journal, 10(4), page 390-397.

16. RGPH. (2014). Note on the first results of the General Census of the Population and the Habitat 2014, High Commissariat of Plans. province of Khenifra.

17. Topanou N. (2012). Management of solid waste in the city of AbomeyCalavi (Benin): characterization and testing of valuation by composting. Thesis for a doctor degree. University of Aix Marseille and the University of Abomey-Calavi. 